\title{
Use of lanreotide in combination with cabergoline or pegvisomant in patients with acromegaly in the clinical practice: The ACROCOMB study
}

Uso de lanreotida en combinación con cabergolina o pegvisomant en la práctica clínica en pacientes con acromegalia: el estudio ACROCOMB

\author{
Manuel Puig-Domingo ${ }^{\mathrm{a}}$, Alfonso Soto ${ }^{\mathrm{b}}$, Eva Venegas ${ }^{\mathrm{b}}$, Ricardo Vilchez ${ }^{\mathrm{c}}$, Concepción \\ Blanco $^{\mathrm{d}}$, Fernando Cordido ${ }^{\mathrm{e}}$, Tomás Lucas ${ }^{\mathrm{f}}$, Mónica Marazuela ${ }^{\mathrm{g}}$, Rosa Casany ${ }^{\mathrm{h}}$, \\ Guillem Cuatrecasas ${ }^{\mathrm{i}}$, Carmen Fajardo ${ }^{\mathrm{j}}$, María Ángeles Gálvez ${ }^{\mathrm{k}}$, Silvia Maraver ${ }^{1}$, Tomás \\ Martín $^{\mathrm{m}}$, Enrique Romero ${ }^{\mathrm{n}}$, Miguel Paja ${ }^{\mathrm{o}}$, Antonio Picó ${ }^{\mathrm{p}}$, Ignacio Bernabeu ${ }^{\mathrm{q}}$, Eugenia \\ Resmini ${ }^{\mathrm{r}}$, on behalf of the ACROCOMB study group
}

\footnotetext{
${ }^{a}$ Hospital Universitario Germans Trias i Pujol, Carretera Canyet, s/n 08916 Badalona, Barcelona, Spain

${ }^{b}$ Hospital Universitario Virgen del Rocío, Av Manuel Siurot, 0, 41013 Sevilla, Spain

${ }^{c}$ Hospital Universitario Virgen de las Nieves, Av de las Fuerzas Armadas, 2, 18014 Granada, Spain

${ }^{d}$ Hospital Universitario Príncipe de Asturias, Carretera Alcalá-Meco, s/n, 28805 Alcalá de Henares, Madrid, Spain

${ }^{e}$ Hospital Universitario A Coruña, As Xubias, 84, 15006 A Coruña, Spain

${ }^{f}$ Hospital Universitario Puerta de Hierro, Calle Manuel de Falla, 1, 28222 Majadahonda, Madrid, Spain

${ }^{g}$ Hospital Universitario La Princesa, Calle de Diego León, 62, 28006 Madrid, Spain

${ }^{h}$ Hospital Lluis Alcanyís, Carretera Xàtiva-Silla, km 2, 46800 Xàtiva, Spain

${ }^{i}$ Centro Médico Teknon, Carrer de Vilana, 12, 08022 Barcelona, Spain

${ }^{j}$ Hospital Universitario La Ribera, Carretera Corbera, km 1, 46600 Alzira, Valencia, Spain

${ }^{k}$ Hospital Universitario Reina Sofía, Avda. Menéndez Pidal, s/n, 14004 Córdoba, Spain

${ }^{l}$ Hospital Clínico Universitario Virgen de la Victoria, Campus Universitario de Teatinos, s/n, 29010, Málaga, Spain

${ }^{m}$ Hospital Universitario Virgen Macarena, Avd. Dr. Fedriani, 3, 41007 Sevilla, Spain

${ }^{n}$ Hospital Clínico Universitario, Av Ramón y Cajal, 3, 47005 Valladolid, Spain

${ }^{\circ}$ Hospital Universitario de Basurto, Avda. de Montevideo $N^{\circ}$ 18, (Carretera N-634), 48013 Bilbao, Spain

${ }^{p}$ Hospital General Universitario de Alicante, Av Pintor Baeza, 12, 03010 Alicante, Spain

${ }^{q}$ Hospital Clínico Universitario, Travesía de Choupana, s/n, 15706 Santiago de Compostela, Spain

${ }^{r}$ Endocrinología, Hospital Sant Pau, Pare Claret, 167, Barcelona, Spain
} 


\begin{abstract}
Purpose.

To describe real-world use of lanreotide combination therapy for acromegaly.

Patients and methods.

ACROCOMB is a retrospective observational Spanish study of patients with active acromegaly treated with lanreotide combination therapy between 2006 and 2011. 108 patients treated at 44 Spanish Endocrinology Departments were analyzed separately: 61 patients received lanreotide/cabergoline (cabergoline cohort) and 47 lanreotide/pegvisomant (pegvisomant cohort).

Results

Patient median age was 50.8 years in the cabergoline cohort and 42.7 years in the pegvisomant cohort. Prior medical treatments were somatostatin analogue (SSA) monotherapy (40 [66\%] patients) or dopamine agonists (7 [11\%] patients) in the cabergoline cohort and SSA (29 [62\%] patients) or pegvisomant monotherapy (16 [34\%] patients) in the pegvisomant cohort. Across both cohorts 12 patients were previously untreated, and prior therapy was unknown/missing in 4 patients. Median duration of combined treatment was 1.6 years $(0.1-6)$ and 2.1 years $(0.4-6.3)$ in the cabergoline and pegvisomant cohorts, respectively. At baseline, median insulin growth factor (IGF)-I values were 149\% upper limit of normal (ULN) (15-505\%) in the cabergoline cohort and $156 \%$ ULN (15-534\%) in the pegvisomant cohort, and decreased to $104 \%$ ULN (13-557\%) p<0.001 and 86\% ULN (23-345\%) p<0.0001, respectively, at end of study (EOS). Normal age-adjusted values of IGF-I were obtained in $48 \%$ of lanreotide/cabergoline-treated patients and $70 \%$ of lanreotide/pegvisomant-treated patients at EOS. There were no significant changes in hepatic, cardiac or glycaemic parameters in either cohort.

Conclusion

In clinical practice lanreotide treatment combinations are useful options for patients with acromegaly when monotherapy is insufficient; particularly, the combination of lanreotide and pegvisomant in patients not controlled with either SSA or pegvisomant alone has high efficacy and is well-tolerated.
\end{abstract}

\title{
Keywords
}

Acromegaly; Lanreotide; Cabergoline; Pegvisomant; IGF-I; Somatostatin analogues

\section{Resumen}

Propósito

Describir el uso de lanreotida en combinación terapéutica en acromegalia en la práctica clínica.

Pacientes y métodos

ACROCOMB es un estudio observacional, retrospectivo, de pacientes con acromegalia activa tratados en centros hospitalarios españoles con lanreotida en combinación con cabergolina o pegvisomant entre 2006 y 2011. Se revisaron los datos clínicos de 108 pacientes tratados en 44 departamentos de endocrinología: 61 pacientes recibieron lanreótido/cabergolina (cohorte cabergolina) y 47 lanreotida/pegvisomant (cohorte pegvisomant).

\section{Resultados}

La edad mediana de los pacientes fue de 50,8 años en la cohorte de cabergolina y 42,7 años en la de pegvisomant. Los tratamientos médicos previos a la combinación con lanreótido fueron análogos de somatostatina (SSA) en monoterapia (40 [66\%] pacientes) o agonistas de la dopamina (7 [11\%] pacientes) en la cohorte de cabergolina y SSA (29 [62\%] pacientes) y pegvisomant en monoterapia (16 [34\%] pacientes) en la de pegvisomant. Doce pacientes no habían recibido tratamiento previo y en 4 pacientes se desconocía la terapia previa. La mediana de duración del tratamiento fue de 1,6 años (0,1-6) y 2,1 años (rango 0,4 a 6,3) en las cohortes de cabergolina y pegvisomant, respectivamente. Al inicio del estudio el valor mediano del factor de crecimiento de insulina-I era 149\% el límite superior normal (LSN) (15-505\%) en la cohorte de cabergolina y 156\% LSN (15-534\%) en la de pegvisomant. Al final del estudio se redujeron a 104\% LSN (13-557\%) p<0,001 y 86\% LSN (23-345\%) p<0,0001, respectivamente. Al final del estudio, se reportaron valores normales de factor de crecimiento de insulina-I ajustados por edad en el $48 \%$ de los pacientes tratados con lanreotida/cabergolina y $70 \%$ de los tratados con lanreotida/pegvisomant. No hubo cambios significativos en los parámetros hepáticos, cardíacos o glucémicos.

Conclusión

En la práctica clínica las combinaciones con lanreotida son una opción útil en el tratamiento de pacientes con acromegalia que no está bien controlada en monoterapia, ya sea con SSA carbegolina o pegvisomant; particularmente, la combinación de lanreotida y pegvisomant tiene una alta eficacia y se tolera bien.

\section{Palabras clave:}

Acromegalia; Lanreotida; Cabergolina; Pegvisomant; IGF-I; Análogos de la somatostatina 


\section{Introduction}

Acromegaly is a rare chronic disorder characterized by increased growth hormone (GH) secretion and elevated insulin-like growth factor-I (IGF-I) levels. ${ }^{1,2}$ In Spain, there is a prevalence of approximately 60 cases per million, but estimates vary between 15.7 and 75.8 in different regions. ${ }^{3-5}$

Three drug classes are available for medical therapy: somatostatin analogues (SSA), dopamine agonists, and GH receptor antagonists, namely pegvisomant. ${ }^{1,2}$ SSAs, such as lanreotide or octreotide are administered as first-line therapy or as second-line therapy in patients undergoing unsuccessful surgery and are currently considered a cornerstone in the treatment of acromegaly. ${ }^{6}$

Historically, dopamine agonists have been used in the treatment of acromegaly but their efficacy as monotherapy is low. ${ }^{2,7}$ Current guidelines recommend that dopamine agonists be considered particularly in patients with mild biochemical activity, such as in the setting of modestly elevated serum IGF-I levels, with or without concomitant treatment with SSAs. ${ }^{1,8}$ Efficacy of the addition of dopamine agonist cabergoline in patients partially responding to SSA, ${ }^{9-14}$ has been reported to be $52 \%$ in terms of normalization of IGF-I as noted in the meta-analysis by Sandret et al. ${ }^{15}$ Pegvisomant is often used as a long-term medical therapy in patients with inadequate response or complete resistance to SSAs. ${ }^{1,16-19}$ In patients with an inadequate response to SSAs, the addition of weekly pegvisomant to full-dose SSA therapy may be effective for further lowering of IGF-I levels. ${ }^{1,20-23}$ and offers the benefit of reduced pegvisomant injection frequency. In a study of long-term weekly pegvisomant in combination with longacting SSAs in 141 patients with acromegaly with persistently elevated IGF-I levels $(>1.2 \times$ upper limit of normal [ULN]) or poor quality of life after 6 months of SSAs monotherapy, 97\% of patients derived efficacy (defined as the lowest measured IGF-I level during treatment). ${ }^{24}$

Evidence from real-life scenarios is a research priority, especially in acromegaly, where multiple large clinical trials are not possible. Specifically, it is important to show that evidence from randomized clinical trials such as treatment schedules, clinical and economic outcomes, could be translated to real-life setting and to show that treatment patterns and clinical outcomes are similar in real-world patients. A systematic review of evidence from real-life scenarios on treatment of acromegaly concluded that although definitions of disease control varied across studies in different real-world settings, approximately half of acromegaly patients have uncontrolled disease. ${ }^{25}$ The aims of this retrospective study were to evaluate the real-world efficacy (biochemical control and tumour size) and safety of the SSA lanreotide treatment combinations for acromegaly in routine clinical practice.

\section{Methods}

ACROCOMB, a retrospective observational multicentre study of the Spanish Society of Endocrinology and Nutrition (SEEN), evaluated the clinical use of lanreotide combined with cabergoline or pegvisomant in patients with active acromegaly. This study included data from the clinical histories of 108 patients treated between 2006 and 2011 in 44 Spanish centres with lanreotide/cabergoline $(\mathrm{N}=61$, cabergoline cohort) or lanreotide/pegvisomant ( $\mathrm{N}=47$, pegvisomant cohort).

Criteria for including a patient into the study were: (1) having received medical treatment for acromegaly with a single agent without achieving adequate control or (2) having a mixed GH and prolactin pituitary adenoma in which combined treatment with lanreotide was indicated as a first pharmacologic option. Additionally, patients should have been treated with lanreotide (Somatuline Autogel injections, IPSEN) and cabergoline or pegvisomant (Somavert injections, Pfizer) following the prescribing information and the specific practices at each centre. Furthermore, patients were required to have a reported GH and IGF-I value before initiating combination treatment and at least one value for GH and IGF-I during combined treatment. IGF-I and GH were measured locally at each centre following local laboratory protocols. The ULN for IGF-I was determined for the immunoassay used at each participating centre. Inmulite (Siemens) was used in approximately $70 \%$ of the patients, while in the other $30 \%$ the Liason (DiaSorin) and the iSYS assay (IDS) were used. The IGF-I values are reported as \% ULN 
and are age-adjusted. Patients with normalized age-adjusted IGF-I values are those with IGF-I values $\leq 100 \%$ ULN

Efficacy was assessed by age-adjusted IGF-I levels, age-adjusted prolactin levels, and GH levels at baseline, after 6 months of treatment and at the end of the study (EOS). EOS was considered as the last registered visit in which a patient was receiving the combined treatment. Information on the radiologic evaluations performed at baseline or at EOS was also recorded if available. A clinically significant reduction in tumour size was defined as a decrease $>2 \mathrm{~mm}$ in microadenoma or a decrease $>20 \%$ in macroadenoma and an increase was defined as growth of $>2 \mathrm{~mm}$ in microadenoma or growth of $>20 \%$ in macroadenoma. Safety was assessed by the detection of the reported adverse events and their potential related causality with lanreotide, cabergoline, or pegvisomant as identified by the treating physician. Specific safety assessments focused on hepatic, cardiac and glycaemic adverse events were also collected. Hepatic function tests included the measurement of alanine aminotransferase (ALT), aspartate aminotransferase (AST), and gamma-glutamyltransferase (GGT) levels at baseline and at EOS. Patients in which pegvisomant was incorporated to their treatment regimen with lanreotide had liver test functions every 4-6 weeks for the first six months of therapy. Hyperglycaemia was assessed by measuring basal glycaemia and $\mathrm{Hb} 1 \mathrm{Ac}$ at baseline and at EOS. When indicated, echocardiograms were used to detect cardiac abnormalities.

Descriptive summary statistics are presented for all variables. The following variables were evaluated in a univariate and multivariate analysis: baseline values of $\mathrm{GH}$, baseline values of IGF-I, radiotherapy, age, final lanreotide dose, final cabergoline dose, and duration of combined treatment. An analysis of variance (ANOVA) of repeated measures (time factor) was used to study the possible evolution of quantitative variables (such as GH). A two-way ANOVA test was used when the effect of another factor was being assessed. In the case of categorical variables, a chi-squares test was used. A multivariate logistic regression was used to analyze the variables' dependency on the normalization of final IGF-I values (normal up to $100 \%$ of ULN). Statistical significance was considered for a $\mathrm{p}$ value $<0.05$. All analyses were performed with the statistical software package SPSS (v20.0).

The ACROCOMB study was conducted in accordance with Good Clinical Practice/regulatory guidelines and relevant local legislation by the Spanish Agency for Medicines and Health Products (AEMPS). The study was authorized by the Ethics Committee of the participating hospitals. The ACROCOMB study was sponsored by Spanish Society of Endocrinology and Nutrition (SEEN) and funded by Ipsen Pharma, Spain. 


\section{Results}

\section{Patient characteristics}

The median patient age was 50.8 years in the cabergoline cohort and 42.7 years in the pegvisomant cohort (Table 1).

Table 1. Baseline characteristics and prior non-pharmacologic treatment.

\begin{tabular}{|c|c|c|}
\hline & $\begin{array}{l}\text { Cabergoline cohort } \\
\mathrm{N}=61\end{array}$ & $\begin{array}{l}\text { Pegvisomant cohort } \\
\mathrm{N}=47\end{array}$ \\
\hline Age $(\operatorname{mean} \pm$ SD) & $50.08 \pm 14.4$ years & $45.3 \pm 14.5$ years \\
\hline \multicolumn{3}{|l|}{ Sex } \\
\hline Male & $20(32.8 \%)$ & $19(40.4 \%)$ \\
\hline Female & $41(67.2 \%)$ & $28(59.6 \%)$ \\
\hline BMI $($ mean \pm SD) & $28.75 \pm 5.9$ & $29.8 \pm 5.2$ \\
\hline Time since diagnosis $(\operatorname{mean} \pm \mathrm{SD})$ & $5.43 \pm 6.7$ years & $7.6 \pm 7.7$ years \\
\hline Maximum diameter at diagnosis $($ mean \pm SD) & $21.91 \pm 11.6 \mathrm{~mm}$ & $25.8 \pm 9.8 \mathrm{~mm}$ \\
\hline \multicolumn{3}{|l|}{ Comorbidities at baseline } \\
\hline Hypertension & $23(37.7 \%)$ & $20(42.6 \%)$ \\
\hline Diabetes & $15(24.6 \%)$ & $16(34.0 \%)$ \\
\hline Cardiopathy & $7(11.5 \%)$ & $4(8.5 \%)$ \\
\hline Gallstone & $6(9.8 \%)$ & $5(10.6 \%)$ \\
\hline Cholecystectomy & $3(4.9 \%)$ & $2(4.3 \%)$ \\
\hline High alcohol intake & $3(4.9 \%)$ & $2(4.3 \%)$ \\
\hline Hepatopathy & $3(4.9 \%)$ & $1(2.1 \%)$ \\
\hline \multicolumn{3}{|l|}{ Prior treatment } \\
\hline Surgery & $50(82.0 \%)$ & $44(93.6 \%)$ \\
\hline \multicolumn{3}{|l|}{ Number of surgeries $(1 / 2)$} \\
\hline 1 & $50(82.0 \%)$ & $40(85.1 \%)$ \\
\hline 2 & $11(18.0 \%)$ & $7(14.9 \%)$ \\
\hline Time since surgery (mean $\pm \mathrm{SD})$ & $5.5 \pm 5.3$ years & $6.1 \pm 7.2$ years \\
\hline Maximum diameter after surgery $($ mean $\pm \mathrm{SD})$ & $16.86 \pm 9.9 \mathrm{~mm}$ & $15.4 \pm 10.3 \mathrm{~mm}$ \\
\hline Radiotherapy (RT) & $24(39.3 \%)$ & $29(61.7 \%)$ \\
\hline Fractionated stereotactic radiotherapy (FSRT) & $10(16.3 \%)$ & $15(31.9 \%)$ \\
\hline Time since FSRT (mean \pm SD) & $4.75 \pm 6.8$ years & $2.3 \pm 2.7$ years \\
\hline Conventional RT & $7(11.5 \%)$ & $7(14.8 \%)$ \\
\hline Time since conventional RT $($ mean \pm SD) & $15.5 \pm 13.3$ years & $12.6 \pm 6.6$ years \\
\hline Radiosurgery & $7(11.5 \%)$ & $7(14.8 \%)$ \\
\hline Time since radiosurgery $($ mean $\pm \mathrm{SD})$ & $3.4 \pm 4.1$ years & $3.2 \pm 2.5$ years \\
\hline
\end{tabular}




\section{Cabergoline cohort}

The main reason reported for receiving the combination of lanreotide and cabergoline was hormonal control in patients partially responsive to SSAs (43 patients, $70.5 \%$ ). Eleven patients (18.0\%) had a mixed $\mathrm{GH} /$ prolactin tumour diagnosis and had not received prior pharmacologic treatment. Prior therapy was unknown/missing in $3(5 \%)$ patients. Prior pharmacologic treatment in the remaining 47 patients was a dopamine agonist in 7 patients $(11.5 \%)$, octreotide in 6 patients $(9.8 \%)$ and lanreotide monotherapy in 34 $(55.7 \%)$ patients.

\section{Pegvisomant cohort}

Failure of monotherapy with SSAs or pegvisomant was also the main reason for administering lanreotide and pegvisomant. Of note, in 4 patients there were 2 medical reasons noted for receiving combination therapy and 1 patient had 3 different reasons. Thirty patients $(67.5 \%)$ were partial SSA responders and 10 patients $(21.3 \%$ ) had insufficient response to the pegvisomant dose received (mean dose of 20mg/day). Six patients achieved biochemical control with either SSA or pegvisomant monotherapy, but received combination therapy for other reasons. Other reasons for receiving lanreotide and pegvisomant were tumour growth control in 5 patients, headache control in 4 patients and patient's convenience/comfort and economic savings, both in 1 patient each. An "other" reason was listed for 1 patient with active acromegaly after surgery and radiotherapy. Overall, with the inclusion of this patient, there were 41 patients $(87.2 \%)$ with poor biochemical control.

Medical treatment immediately prior to receiving lanreotide and pegvisomant was long-acting lanreotide in 26 patients $(55.3 \%)$ and pegvisomant in 16 patients $(34.0 \%)$. Two patients were receiving long-acting octreotide and 1 patient was receiving lanreotide and cabergoline before switching to the combination of lanreotide and pegvisomant. There was only 1 patient who was not receiving any medical treatment and concomitantly initiated both lanreotide and pegvisomant; the reason to initiate treatment with both drugs was not specified in this particular case. Furthermore, there was 1 patient for whom there were no data on pharmacological treatment immediately prior to initiating the combination.

\section{Treatment}

The mean (median [range]) duration of treatment with lanreotide and cabergoline was $2.3 \pm 1.9$ years (1.6 years [0.1-6]), and it was $2.5 \pm 1.7$ years $(2.1$ years [0.4-6.3]) with lanreotide and pegvisomant.

\section{Cabergoline cohort}

Throughout the study, the median doses of lanreotide in the cabergoline cohort increased slightly from $90 \mathrm{mg} / \mathrm{month}$ at baseline to $120 \mathrm{mg} / \mathrm{month}(60-240)$ at EOS. The mean dose of lanreotide was $95.7 \pm 25.1 \mathrm{mg} / \mathrm{month}$ at baseline and $109.2 \pm 38.2 \mathrm{mg} / \mathrm{month}$ at EOS. There were several patients receiving an extended lanreotide treatment regimen (every 6 or every 8 weeks) at baseline (7 patients, $11.5 \%$ ) and at EOS (8 patients, 13.1\%). Furthermore, 26 patients $(42.6 \%)$ were receiving $<120 \mathrm{mg} / \mathrm{month}$ lanreotide at baseline and 14 patients $(23.0 \%)$ at EOS. The median weekly dose of cabergoline $(1.0 \mathrm{mg} / \mathrm{week})$ did not change throughout the study, ranging from $0.25-7$ at baseline to $0.25-14$ at EOS. There was an increase in the mean cabergoline dose from $1.2 \pm 1.1 \mathrm{mg} /$ week at baseline to $1.9 \pm 2.3 \mathrm{mg} / \mathrm{week}$ at EOS. The initial and final dosing regimens of lanreotide and cabergoline can be found in Fig. 1. 

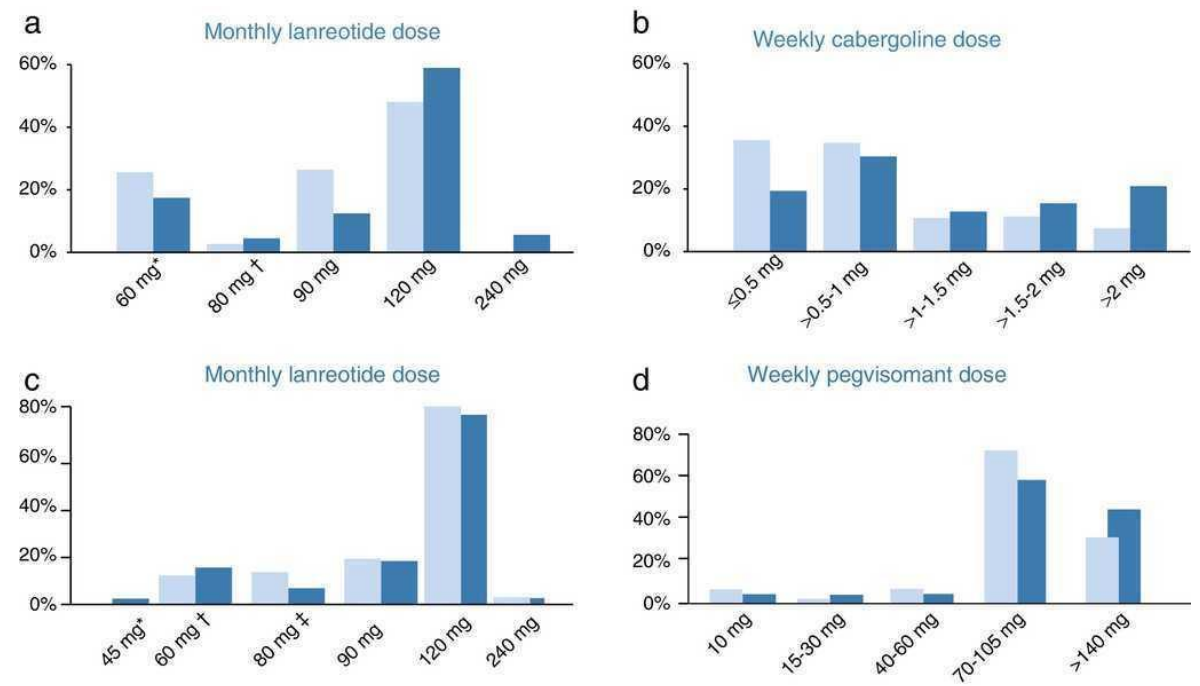

Baseline dose $=$ EOS dose

Figure 1. Doses of lanreotide (a) and cabergoline (b) at baseline and end-of-study (EOS) in the cabergoline cohort and doses of lanreotide (c) and pegvisomant (d) at baseline and EOS in the pegvisomant. *Includes 10 patients receiving $60 \mathrm{mg} / 4 \mathrm{wk}$ and 6 patients receiving $120 \mathrm{mg} / 8 \mathrm{wk}$ at baseline as well as 6 patients receiving $60 \mathrm{mg} / 4 \mathrm{wk}$ and 5 patients receiving $120 \mathrm{mg} / 8 \mathrm{wk}$ at EOS. $\dagger$ Includes 1 patients receiving $120 \mathrm{mg} / 6 \mathrm{wk}$ at baseline and 3 patients receiving $120 \mathrm{mg} / 6 \mathrm{wk}$ at EOS. EOS: end of study. *Includes 1 patient receiving $90 \mathrm{mg} / 8 \mathrm{wk}$ at EOS. $†$ Includes 2 patients receiving $60 \mathrm{mg} / 4 \mathrm{wk}, 3$ patients receiving $120 \mathrm{mg} / 8 \mathrm{wk}$ at baseline and 2 patients receiving $90 \mathrm{mg} / 6$ week, 4 patients receiving $120 \mathrm{mg} / 8 \mathrm{wk}$ at EOS. *Includes 5 patients receiving $120 \mathrm{mg} / 6 \mathrm{wk}$ at baseline and 3 patients receiving $120 \mathrm{mg} / 6$ week at EOS.

\section{Pegvisomant cohort}

The median monthly lanreotide dose did not change in the pegvisomant cohort. It was $120 \mathrm{mg} / \mathrm{month}$ (range $60-240 \mathrm{mg} / \mathrm{month}$ ) at baseline and $120 \mathrm{mg} / \mathrm{month}$ (range $45-240 \mathrm{mg} / \mathrm{month}$ ) at EOS. The mean dose of lanreotide was $107.0 \pm 29.2 \mathrm{mg} / \mathrm{month}$ at baseline and $106.3 \pm 30.9 \mathrm{mg} / \mathrm{month}$ at EOS. An extended regimen of lanreotide (every 6 or every 8 weeks instead of monthly) was administered to 8 patients $(17.0 \%)$ at baseline and to 8 patients $(17.0 \%)$ at EOS. Furthermore, 9 patients $(19.1 \%)$ were receiving $<120 \mathrm{mg} /$ month lanreotide at baseline and 8 patients $(17.0 \%)$ at EOS. The median/mean weekly pegvisomant doses increased from $70 \mathrm{mg}$ (range $10-210 \mathrm{mg}) / 91.7 \pm 48.7 \mathrm{mg}$ at baseline to $105 \mathrm{mg}$ (10$210) / 104.7 \pm 50.0 \mathrm{mg}$ at EOS. The initial and final dosing regimens of lanreotide and pegvisomant can be found in Fig. 1. 


\section{Efficacy}

\section{Biochemical control}

IGF1 decreased from baseline to EOS in the majority of patients (Fig. 2).

a
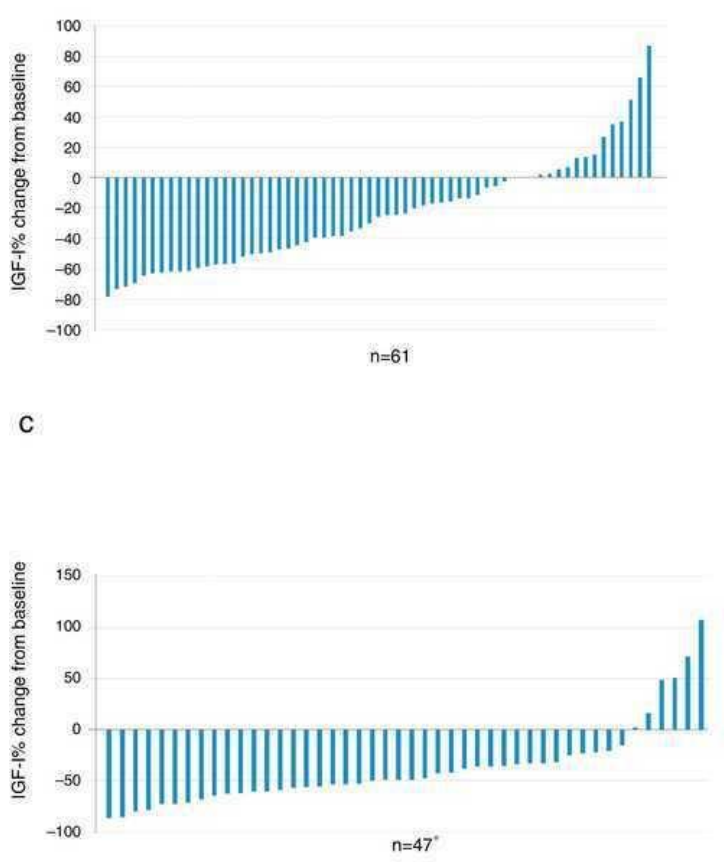

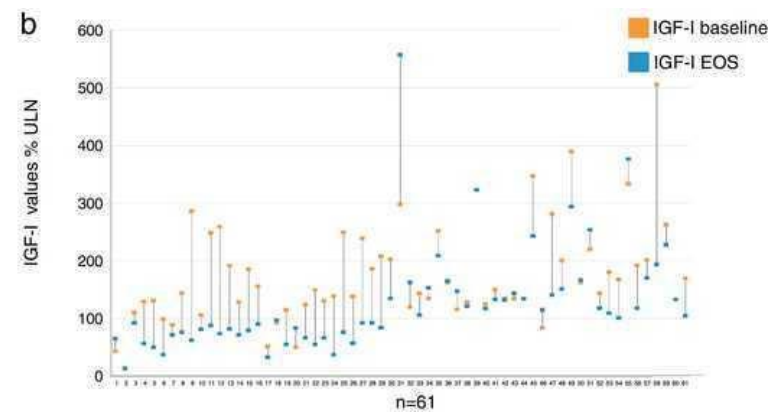

d

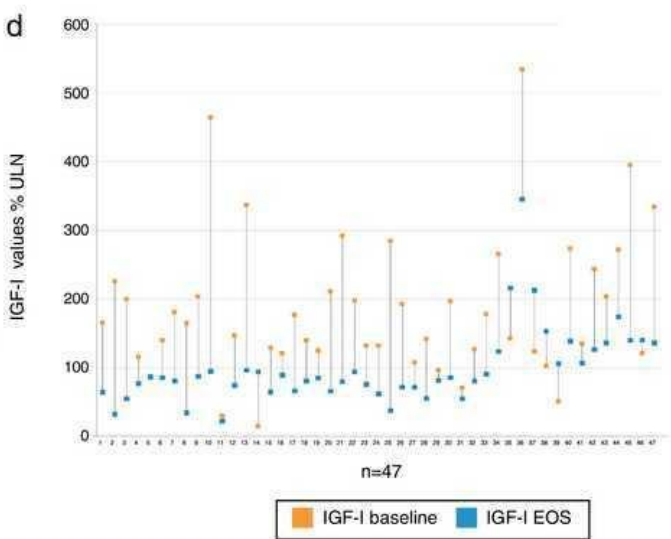

Figure 2. Percent change vs baseline value of IGF-I in each individual patient, overall (a) and value-specific (b) in the cabergoline cohort and overall (c) and value-specific (d) in the pegvisomant cohort. Patient 2, 39, and 60 had a negligible change from baseline to EOS and do not show up as bars in (a). *There was one patient (see number 14 in d) with a baseline value of $15 \%$ and increased to $94 \%$ ULN; therefore there was a $526 \%$ change from baseline. This patient is not plotted in c. IGF-I: insulin growth factor; EOS: end of study.

\section{Cabergoline cohort}

The combination of lanreotide and cabergoline treatment led to significant decrease in both the median IGF-I and prolactin values (Table 2), and to an increase of the percentage of patients with values of $\mathrm{GH}<2.5 \mathrm{ng} / \mathrm{ml}$, with normal age-adjusted values of IGF-I and prolactin, as well as those reaching both GH and IGF-I treatment goals (Fig. 3). Few patients reached a level of GH <1.0ng/ml. By the EOS, 29 patients $(48 \%)$ had normalized IGF-I values. In 8 patients with normal baseline values of IGF-I, the reasons for starting the combination were high prolactin levels and $\mathrm{GH}$ values $>2.5 \mathrm{ng} / \mathrm{ml}$. It is important to note that among the 32 patients $(52 \%)$ that did not have normalized values of IGF-I at EOS, 2 were receiving monthly doses of lanreotide $<120 \mathrm{mg}$ and 18 patients were receiving weekly doses of cabergoline $<2 \mathrm{mg}$. At EOS both the lanreotide and the cabergoline doses were lower in patients with normalized IGF-I (lanreotide, median: 90mg/month [range 60-120mg/month]; mean: $89.0 \pm 24.31 \mathrm{mg} / \mathrm{month}$ and cabergoline, median: $1.0 \mathrm{mg} / \mathrm{week}$ [range $0.25-5.0 \mathrm{mg} / \mathrm{week}$ ]; mean: 
$1.4 \pm 1.2 \mathrm{mg} /$ week) than in patients with elevated IGF-I (lanreotide, median: $120 \mathrm{mg} / \mathrm{month}$ [range 60 $240 \mathrm{mg} / \mathrm{month}$ ]; mean: $127.5 \pm 39.6 \mathrm{mg} / \mathrm{month}$ and cabergoline, median: $1.5 \mathrm{mg} /$ week [range 0.25 $14 \mathrm{mg} /$ week]; mean:2.4 $\pm 2.8 \mathrm{mg} /$ week).

Table 2. Biochemical values.

\begin{tabular}{llll}
\hline & Baseline & 6 months & EOS \\
\hline Cabergoline cohort (N=61) & & & \\
GH, median (25th-75th percentile) & & & \\
IGF-I, median ULN (range) & $4 \mathrm{ng} / \mathrm{ml}(2-8)$ & $3 \mathrm{ng} / \mathrm{ml}(1-7)^{* *}$ & $2 \mathrm{ng} / \mathrm{ml}(1-4)^{*}$ \\
& $149 \% \mathrm{ULN}$ & $117 \% \mathrm{ULN}$ & $104 \% \mathrm{ULN}^{*}$ \\
Prolactin, median ULN (range) & $(15-505 \%)$ & $(13-557 \%)$ & $(13-557 \%)$ \\
& $88 \% \mathrm{ULN}$ & $7 \% \mathrm{ULN}^{*}$ & $5 \% \mathrm{ULN}^{*}$ \\
Pegvisomant cohort (N=47) & $(0-4000 \%)$ & $(0-233 \%)$ & $(0-807 \%)$ \\
IGF-I, median ULN (range) & & & \\
& $165 \% \mathrm{ULN}$ & $85 \% \mathrm{ULN}^{*}$ & $86 \% \mathrm{ULN}^{*}$ \\
& $(15-534 \%)$ & $(11-263 \%)$ & $(23-345 \%)$ \\
\hline
\end{tabular}

EOS: end of study; GH: growth hormone; IGF: insulin growth factor; ULN: upper limit of normal. $* \mathrm{p}<0.001$ vs baseline.

$* * \mathrm{p}<0.022$ vs baseline.

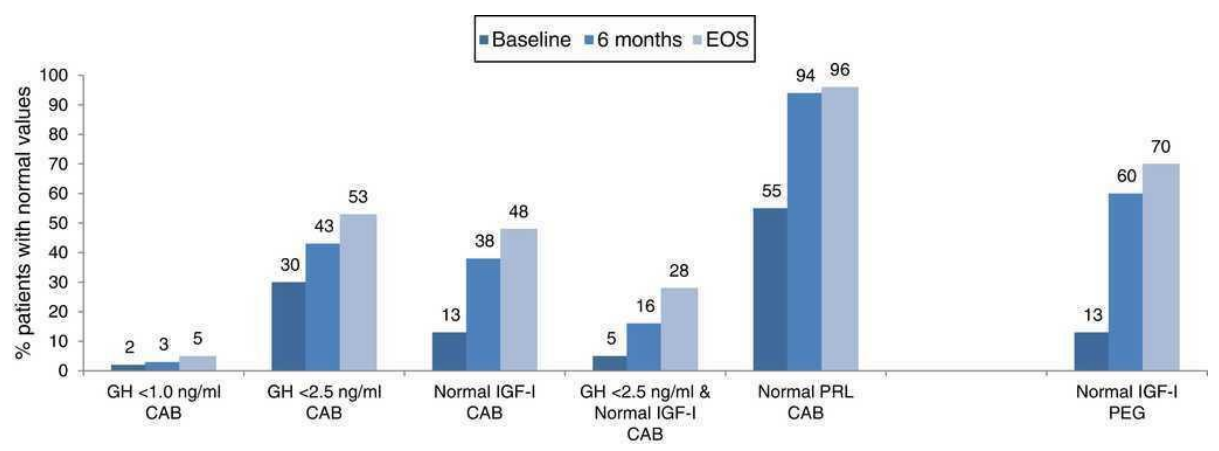

Figure 3. Patients with age-adjusted normalized biochemical values. CAB: cabergoline cohort; EOS: end of study GH: growth hormone; IGF-I: insulin growth factor; PEG: pegvisomant cohort; PRL: prolactin.

In a multivariate analysis, a higher probability of normalization of IGF-I levels at EOS was associated with higher final dose of lanreotide and longer duration of treatment (Table 3). In the multivariate analysis, prior radiotherapy did not affect the biochemical outcome $(\mathrm{p}=0.072)$. However, at the EOS timepoint, fewer patients without prior radiotherapy had normalized IGF-I values (38\% vs $48 \%$ in the overall cabergoline cohort; Table 4). 
Table 3. Univariate and multivariate analyses.

\begin{tabular}{|c|c|c|c|c|c|}
\hline \multirow[b]{2}{*}{ Variables } & \multicolumn{4}{|c|}{ Cabergoline cohort } & \multirow{2}{*}{$\begin{array}{l}\text { Pegvisomant cohort } \\
\text { Univariate } \\
\text { p value }\end{array}$} \\
\hline & $\begin{array}{l}\text { Univariate } \\
\mathrm{p} \text { value }\end{array}$ & $\begin{array}{l}\text { Multivariate } \\
\text { p value }\end{array}$ & OR & $95 \% \mathrm{CI}$ & \\
\hline Sex & 0.586 & - & - & - & 0.195 \\
\hline Baseline $\mathrm{GH}$ value & 0.395 & - & - & - & 1.0 \\
\hline Baseline IGF-I value & 0.022 & 0.022 & 0.041 & $0.003-0.632$ & 0.653 \\
\hline Radiotherapy & 0.072 & - & - & - & 0.516 \\
\hline Age & 0.941 & - & - & - & 0.583 \\
\hline Dose of lanreotide at EOS & $<0.0001$ & $<0.0001$ & 1.071 & $1.033-1.111$ & 0.322 \\
\hline Dose of cabergoline at EOS & 0.065 & - & - & - & 0.566 \\
\hline Duration of treatment & 0.012 & 0.004 & 0.490 & $0.301-0.798$ & 0.004 \\
\hline
\end{tabular}

CI: confidence interval; GH: growth hormone; IGF: insulin growth factor; EOS: end of study; OR: odds ratio.

* The model is predictive (AUCROC $=0.917, \mathrm{p}<0.001$ ) and is correct because the adjustment bond (test of Hosner \& Lemeshow) is not significant $(\mathrm{p}=0.513)$ indicating that there are no differences between the observations and the predictions.

Table 4. IGF-I values in patients who had not received prior radiotherapy.

\begin{tabular}{|c|c|c|c|}
\hline & Baseline & 6 months & EOS \\
\hline Cabergoline cohort $(n=37)$ & $\mathrm{n}=37$ & $\mathrm{n}=37$ & $\mathrm{n}=37$ \\
\hline IGF-I values, median ULN (range) & $\begin{array}{l}144 \% \text { ULN } \\
(15-505 \%)\end{array}$ & $\begin{array}{l}117 \% \text { ULN } \\
(13-376 \%)\end{array}$ & $\begin{array}{l}117 \% \text { ULN } \\
(13-376 \%)\end{array}$ \\
\hline Normalized IGF-I, n (\%) & $5(13.5 \%)$ & $15(40.5 \%)$ & $14(37.8 \%)$ \\
\hline Pegvisomant cohort $(n=18)$ & $\mathrm{n}=18$ & $\mathrm{n}=18$ & $\mathrm{n}=18$ \\
\hline IGF-I values, median ULN (range) & $\begin{array}{l}145 \% \text { ULN } \\
(85-464 \%)\end{array}$ & $\begin{array}{l}69 \% \text { ULN } \\
(41-263 \%)\end{array}$ & $\begin{array}{l}85.5 \% \text { ULN } \\
(35-216 \%)\end{array}$ \\
\hline Normalized IGF-I, n (\%) & $1(5.6 \%)$ & $14(77.8 \%)$ & $14(77.8 \%)$ \\
\hline
\end{tabular}

EOS: end of study; IGF: insulin growth factor; ULN: upper limit of normal.

\section{Pegvisomant cohort}

Treatment with lanreotide and pegvisomant significantly decreased median IGF-I values after 6 months of treatment and at EOS (Table 2) and led to an increase of patients with normal age-adjusted values of IGF-I, by the EOS, 33 patients (70.2\%) had normalized IGF-I values (Fig. 3).

As noted earlier, the combination of lanreotide and pegvisomant was administered mainly due to biochemical failure of SSA $(n=30)$ or pegvisomant $(n=10)$ monotherapy. In these 40 patients, median IGF-I values were $172 \%$ ULN (71-534\%) at baseline and significantly decreased to 90\% ULN (41$263 \%)$ at 6 months and $86 \%$ ULN (33-345\%) at EOS. 
Of the 14 patients $(29.8 \%)$ without normalized values of IGF-I at EOS, 4 patients were receiving doses of lanreotide $<120 \mathrm{mg} / \mathrm{month}$ and 9 patients were receiving doses of pegvisomant $<140 \mathrm{mg} / \mathrm{week}$, below the theoretical maximal therapeutic dose of $210 \mathrm{mg} / \mathrm{week}$. At EOS both the lanreotide and the pegvisomant doses were lower in patients with normalized IGF-I (lanreotide, median: 120mg/month [range $45-120 \mathrm{mg} / \mathrm{month}$ ]; mean: $102.6 \pm 24.1 \mathrm{mg} / \mathrm{month}$ and pegvisomant, median: $105 \mathrm{mg} / \mathrm{week}$ [range 10-210mg/week]; mean: $101.7 \pm 46.9 \mathrm{mg} /$ week) than in patients with elevated IGF-I (lanreotide, median: $120 \mathrm{mg} / \mathrm{month}$ [range 60-240mg/month]; mean: $115.0 \pm 42.7 \mathrm{mg} / \mathrm{month}$ and pegvisomant, median: $105 \mathrm{mg} /$ week [range 15-210mg/week]; mean: $111.9 \pm 58.0 \mathrm{mg} /$ week).

In a univariate analysis, longer treatment duration was significantly associated with a higher normalization of IGF-I levels $(\mathrm{p}=0.004)$. The mean treatment duration was $2.9 \pm 1.7$ years in patients with normal age-adjusted IGF-I $(\leq 100 \%)$ and in patients with elevated IGF-I $(>100 \%)$ the mean treatment duration was $1.6 \pm 1.2$ years. The IGF-I levels did not decrease in 7 patients: 2 of these patients had normal age-adjusted IGF-I $(\leq 100 \%)$, both at baseline and at EOS; 1 of these patients had normal age-adjusted IGF-I at baseline that increased slightly to $106 \%$ ULN; the IGF-I values in the other 4 patients were above $100 \%$ ULN at baseline and had increases that ranged from $16 \%$ to $71 \%$. The pharmacologic treatment that these 7 patients were receiving immediately prior to the lanreotide/pegvisomant combination was monotherapy with lanreotide $(n=2)$, octreotide $(n=1)$, and pegvisomant $(n=4)$. At EOS, in these 7 patients the mean monthly dose of lanreotide was $124.3 \pm 55.9 \mathrm{mg}$ and the mean weekly dose of pegvisomant was $118.6 \pm 74.9 \mathrm{mg}$. Five patients were receiving daily pegvisomant and 2 patients were receiving pegvisomant on a weekly basis at EOS.

\section{Tumour size}

Treatment with the lanreotide combinations led to tumour size decrease or stabilization.

Cabergoline cohort. At EOS 34 of 41 (82.9\%) patients had significant residual tumour by MRI. After treatment with lanreotide and cabergoline, 7 of $34(20.5 \%)$ patients had a reduction in tumour size, while in 26 of $34(76.5 \%)$ patients the tumour remained stable, and in 1 of $34(2.9 \%)$ patients the tumour size increased.

Pegvisomant cohort. At EOS 29 of $36(80.6 \%)$ patients had residual tumour by MRI. After treatment with lanreotide and pegvisomant, 2 of $29(6.9 \%)$ patients had a reduction, 26 of $29(89.7 \%)$ patients had stabilization, and 1 of $29(3.4 \%)$ patients had an increase in tumour size. 


\section{Safety}

There were no significant changes in hepatic or glycaemic parameters (Table 5).

Table 5. Specific safety assessments.

\begin{tabular}{|c|c|c|c|}
\hline & Baseline & EOS & $p$ value \\
\hline \multicolumn{4}{|l|}{ Cabergoline cohort $(\mathrm{N}=61)$} \\
\hline \multicolumn{4}{|l|}{ Liver enzymes } \\
\hline AST (normal/1-2.9 ULN) & $\mathrm{n}=49(49 / 0)$ & $\mathrm{n}=54(54 / 0)$ & \\
\hline ALT (normal/1-2.9 ULN) & $\mathrm{n}=49(48 / 1)$ & $\mathrm{n}=54(52 / 2)$ & 1 \\
\hline GGT (normal/1-2.9 ULN) & $\mathrm{n}=46(43 / 3)$ & $\mathrm{n}=51(49 / 2)$ & 1 \\
\hline Cardiac assessment with echocardiogram & $\mathrm{n}=13$ & $\mathrm{n}=14$ & \\
\hline Abnormal valve & $4(30.8 \%)$ & $4(28.6 \%)$ & \\
\hline Ventricular hypertrophy & $5(38.5 \%)$ & $3(21.4 \%)$ & \\
\hline Basal glycaemia, median (range) & $94 \mathrm{mg} / \mathrm{dl}(68-154)$ & $97 \mathrm{mg} / \mathrm{dl}(48-163)$ & 0.471 \\
\hline HbA1c, median (range) & $6 \%(5-8)$ & $6 \%(5-8)$ & 0.248 \\
\hline \multicolumn{4}{|l|}{ Pegvisomant cohort $(\mathrm{N}=47)$} \\
\hline \multicolumn{4}{|l|}{ Liver enzymes } \\
\hline AST (normal/1-2.9 ULN) & $\mathrm{n}=39(39 / 0)$ & $\mathrm{n}=38(37 / 1)$ & \\
\hline ALT (normal/1-2.9 ULN) & $\mathrm{n}=40(39 / 1)$ & $\mathrm{n}=39(37 / 2)$ & 1 \\
\hline GGT (normal/1-2.9 ULN) & $\mathrm{n}=37(35 / 2)$ & $\mathrm{n}=37(35 / 2)$ & 1 \\
\hline Cardiac assessment with echocardiogram & $\mathrm{n}=11$ & $\mathrm{n}=5$ & \\
\hline Abnormal valve & $5(45.5 \%)$ & $2(40.0 \%)$ & \\
\hline Ventricular hypertrophy & $4(36.4 \%)$ & $1(20.0 \%)$ & \\
\hline Basal glycaemia, median (range) & $103 \mathrm{mg} / \mathrm{dl}(77-202)$ & $99 \mathrm{mg} / \mathrm{dl}(75-213)$ & 0.291 \\
\hline HbA1c, median (range) & $6.5 \%(5-10)$ & $6 \%(5-9)$ & 0.593 \\
\hline
\end{tabular}

ALT: alanine transaminase; AST: aspartate transaminase; GGT: gamma-glutamyl transferase.

\section{Cabergoline cohort}

There were 54 adverse events reported in $36(59.0 \%)$ of the patients. The main adverse event during treatment was headache, reported 17 times in 9 patients, and apparently unrelated to treatment with lanreotide or cabergoline (as determined by the treating physician). Headache was reported as an adverse event once in 5 patients, twice in 2 patients, and four times in 2 patients. Further analyses of the patients with headache did not reveal a correlation with disease control. Among these 9 patients, normalized IGF-I levels were reported in $1(11 \%)$ patient at baseline and in $5(56 \%)$ patients after 6 months of treatment and at EOS. Among the 52 patients that did not report headache as an adverse event, there were $7(14 \%)$ patients with normalized IGF-I at baseline, 18 (35\%) after 6 months, and 24 (46\%) at EOS. Other adverse events reported included local reactions at the injection site (6 reports, all related to lanreotide), abdominal pain (6 reports, all related to lanreotide), biliary sludge ( 5 reports and related to lanreotide in at least 4), diarrhoea (4 reports, all related to lanreotide), nausea (3 reports and related to lanreotide in 2). There was 1 report each of hypotension, valvulopathy, and somnolence, all related to cabergoline. 


\section{Pegvisomant cohort}

Forty-one adverse events were reported in $22(46.8 \%)$ of the patients. The main adverse event reported during the study was local reactions at the injection site, including lipohypertrophy, reported 7 times; it was deemed twice related to treatment with lanreotide and twice to pegvisomant. Other adverse events reported included headache (6 reports, pegvisomant-related in 2), abdominal pain (6 reports, lanreotide-related in 2 and pegvisomant-related in 3), nausea (3 reports, unrelated to treatment per clinical criteria of the treating physician), biliary sludge ( 2 reports, unrelated to treatment per clinical criteria of the treating physician), biliary calculi ( 2 reports and related to lanreotide in 1). There was 1 report each of tumour growth as an adverse event, diarrhoea, and hepatotoxicity.

The reasons for treatment discontinuation in the cabergoline cohort included lack of efficacy $(n=8)$, patient decision $(n=2)$, patient death $(n=1)$ and postradiotherapy improvement $(n=1)$ and in the pegvisomant cohort included lack of efficacy $(n=2)$, patient decision $(n=2)$, postradiotherapy improvement $(n=2)$ and patient death $(n=1)$. In 2 of the 8 patients that discontinued due to lack of efficacy the cabergoline dose was very low $(0.5 \mathrm{mg} /$ week $)$ at EOS. The status of 3 lanreotide/cabergoline-treated patients and 2 lanreotide/pegvisomant-treated patients was unknown due to loss of follow-up. There were no discontinuations due to safety reasons in the cabergoline cohort and there was 1 in the pegvisomant cohort. Neither the treatment discontinuations nor the patient deaths in either cohort were considered by the treating physicians to be related to treatment.

\section{Discussion}

In this large retrospective series of patients with acromegaly reflecting the use of lanreotide combination therapy in routine clinical practice, both the combination with cabergoline and the combination with pegvisomant appear to be clinically useful in many patients with active acromegaly not fully controlled on monotherapy. Normalization of IGF-I values was reported in approximately half of the patients that received lanreotide/cabergoline and in $70 \%$ of patients receiving lanreotide/pegvisomant. However, even with the best clinical handling with currently available drugs, $50 \%$ of patients in the cabergoline cohort and $30 \%$ in the pegvisomant cohort remained uncontrolled at EOS. Overall, these data highlight the heterogeneous nature of the disease, a fact well known by treating clinicians. These clinicians must decide on the best treatment for each patient, but are not yet able to rely on biomarkers for predicting a positive therapeutic result in the clinical practice.

The result in the cabergoline cohort is similar to what was reported in a meta-analysis of 5 studies of cabergoline and SSA treatment in 77 patients, where $52 \%$ of patients achieved normal IGF-I levels ${ }^{15}$ and to what has been reported in other studies on this combination. ${ }^{9-14}$ In a long-term retrospective study of 66 acromegalic patients partially responding to octreotide, the addition of cabergoline led to a $73 \%$ of the patients achieving a GH $<2.5 \mathrm{ng} / \mathrm{mL}, 34 \%$ of the patients an IGF- $1<1.2 \times$ ULN and $30.2 \%$ reaching both biochemical goals. $^{26}$ The rates of IGF-I normalization in the pegvisomant cohort are lower than those reported in controlled clinical studies with this combination therapy, which typically report biochemical response in $\geq 95 \%$ of patients, ${ }^{20,21,24,27}$ but are similar to what has been reported in the study by van der Lely et al., ${ }^{23}$ which specifically selected patients resistant to SSAs, and a recent Italian retrospective study of clinical practice, ${ }^{28}$ both of which had a patient population comparable to the ACROCOMB study population.

Approximately one third to one half of patients receiving treatment with SSAs have partial but insufficient long-term disease control; among these patients, approximately 10-25\% can be considered highly medically resistant, ${ }^{6}$ meaning a very poor response to maximal doses of SSAs. A challenge as well as a clear clinical need in acromegaly is to define biomarkers that could reasonably identify responders and non-responders to SSA therapy in order to save time and expenses when treating our patients with SSAs, the accepted first option for medical treatment of acromegaly. Moreover, considering that acromegaly is usually diagnosed late in the disease evolution, adding delays in controlling GH hypersecretion leads to a further comorbility development. While SSAs treatment is the cornerstone of 
acromegaly medical management, it is important to be able to provide effective treatment regimens to patients in which hormonal control is not achieved with SSAs monotherapy. ${ }^{6}$ Hormonal control in patients partially responding to SSAs was the main reason for receiving combination therapy with an additional drug. However, a significant proportion of patients was not receiving the full dose of lanreotide or was receiving lanreotide on an extended treatment regimen $(>q 4 w)$. These situations reflect the reality of clinical practice, in which therapeutic agents are administered at lower doses than those theoretically possible, potentially due to inadequate dosing by the prescribing physicians, inadequate patient compliance, or due to side effects not allowing up titration. ${ }^{17,18,29,30}$ Using lower doses of lanreotide and cabergoline/pegvisomant might explain, at least in part, the lack of IGF-I normalization in a subset of patients in the ACROCOMB study. Potentially, the use of higher doses of SSAs or increasing the administration frequency could help to achieve a higher response to treatment, as reported in the Italian randomized controlled study that evaluated the biochemical efficacy of increasing SSAs frequency or dose in patients with persistently uncontrolled acromegaly despite conventional titration SSAs therapy. ${ }^{31}$

More than half of the patients in the cabergoline cohort that did not achieve IGF-I normalization were receiving cabergoline doses below $<2 \mathrm{mg} /$ week, lower than what has been reported to be effective for combination treatment with SSAs. This implies a certain degree of therapeutic inertia in clinical practice if we take into account that cabergoline was started after lanreotide in most of the patients. Moreover, one third of the patients in the pegvisomant cohort were receiving pegvisomant monotherapy and failed to achieve therapeutic goals before the lanreotide combination was started; it is remarkable that so many patients were receiving pegvisomant monotherapy, considering that SSA monotherapy is the usual recommended first-line treatment. It is notable that many of the patients with poor biochemical control had not been titrated to maximal doses of lanreotide or pegvisomant during monotherapy; thus it is possible to speculate that higher efficacy might have been attained in the present study if more patients would have been titrated to a higher dose. In a survey of European physicians treating patients with acromegaly that evaluated their perceived definition of biochemical control and real-world treatment decision making, half of the physicians responding considered it acceptable for a patient to have IGF-I $1 \times$ $>$ ULN, and one fifth considered IGF-I $\geq 1.5 \times$ ULN acceptable. ${ }^{32}$ This suggests a therapeutic inertia situation although the specific reasons why lanreotide or cabergoline/pegvisomant doses were not up titrated are not known.

In our study, the combined treatment with lanreotide was well tolerated without significant liver enzyme elevations, cardiac abnormalities, or glucose alterations. An increased risk of cardiac valve

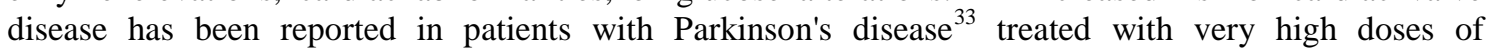
cabergoline. However, a study that specifically evaluated the incidence of cardiac abnormalities in a series of 42 patients with acromegaly treated with cabergoline did not find a higher incidence of valve abnormalities. $^{34,35}$ Moreover, another large cross-sectional study from the UK did not support an association between the use of dopamine agonists for the treatment of hyperprolactinemia and cardiac valvulopathy. ${ }^{36}$ Hypertransaminasemia is one of the most frequently described adverse events of pegvisomant, ranging from $1.2 \%$ to $38 \%$, with higher rates of occurrence when patients receive a combination with an SSA, ${ }^{18-21,37}$ especially within the first year of combination treatment. ${ }^{24}$ Liver enzyme elevations appear to be reversible and normalize either with continued treatment or after discontinuation of therapy. It is noteworthy that there were no increases in transaminase levels to more than 3 times the ULN in this study and the rates of clinically relevant liver enzyme elevations were lower than in other studies with pegvisomant. ${ }^{21,23,27}$ Furthermore, although increases in blood glucose are a known effect of $\mathrm{SSAs}^{38,39}$ in our study there were no changes in glycaemia and Hb1Ac.

Limitations of our study include its retrospective and observational design. Importantly, data were collected retrospectively from several centres using different local laboratories and assays with different sensitivities to measure GH and IGF-I and it is widely recognized that there tends to be a lack of consistency between results from different labs and assays; however, taken as a whole, results reflect what occurs in the clinical practice setting. Moreover, our study has a large number of patients and provides a realistic profile of the efficacy and safety of lanreotide combination therapy in clinical practice across many Spanish centres. In this sense, the rate of IGF-I normalization is high for clinical series, even 
though in our study neither the patient population nor the treatment provided by the physicians were homogeneous, as evidenced by the lower doses of medication received in certain cases.

Overall, our study supports a more relevant role of drug combination in the treatment algorithm of acromegaly after insufficient SSA monotherapy response. Future studies involving the definition of response biomarkers to specific drugs are required in order to help clinicians in the process of treatment decision allowing a quicker normalization of biochemical and hormonal parameters of acromegalic patients. ${ }^{40}$

\section{Declaration of funding}

Sponsored by Spanish Society of Endocrinology and Nutrition (SEEN); Funding by a grant from Ipsen Pharma, Spain.

\section{Conflict of interest}

No conflict of interest: RV, CB, RC, CF, SM, TM, TL, MM.

Conflicts of interest include:

- Employment and consultancies: MP-D: consultancies from Pfizer.

- Grants, fees and honoraria: MP-D has received lecture honoraria from Novartis, Pfizer and Ipsen; FC: has received lecture honoraria from Novartis and Pfizer and unrestricted research grants from Ipsen Pharma; MP: speaker fees from Ipsen and Pfizer; AS: Clinical trials and donations for investigator-initiated research projects by Ipsen, Novartis and Pfizer; AP: advisory board Pfizer; IB: Advisory fees: Pfizer; research grants: Pfizer; lectures fees: Pfizer, Novartis.

- Board membership: MP-D: Pfizer.

\section{Acknowledgements}

We thank the ACROCOMB study group investigators: Mariano Álvarez, Cristina Álvarez-Escolà, Ignacio Bernabeu, Bettina Biagetti, Concepción Blanco, Irene Burgasé, Fernando Luís Calvo García, Rosa Casany, Fernando Córdido, Guillem Cuatrecases, Juan Ramón Domínguez, Alejandra Durán Rodríguez, Fidel Jesús Enciso, Carmen Fajardo, Pablo Fernández, Marta Fernández, Alberto Fernández, M. Ángeles Gálvez, Juan Antonio García Arnés, Honorato García Fernández, Santiago García Torres, Alfonso Gentil, José Manuel Gómez, M. Ángeles Gonzalo, Tomás Lucas Morante, Gonzalo Maldonado, Alfonso Maldonado, Silvia Maraver, Mónica Marazuela Azpiroz, Tomás Martín, M. Purificación Martínez-Icaya, J. Antonio Mato, Edelmiro Menéndez, Francisco Morales, José Carlos Padillo, Miguel Paja, Isabel Pavón, Begoña Pérez, Diego Peteiro, Inmaculada Recás Planellas, Enrique Romero, Pedro Jesús Rozas, Isabel Salinas, Aranzazu Sebastián, Gemma Sesmilo, M. Luisa Surroca, Santiago Tofé Povedano, Elena Torres, Eva Venegas, Ricardo Vílchez, Carles Villabona, Rocío Villar, Susan Webb.

\section{References}

1. Katznelson L, Atkinson JL, Cook DM, Ezzat SZ, Hamrahian AH, Miller KK. American Association of Clinical Endocrinologists medical guidelines for clinical practice for the diagnosis and treatment of acromegaly - 2011 update. Endocr Pract. 2011;17 Suppl 4:1-44.

2. Manjila S, Wu OC, Khan FR, Khan MM, Arafah BM, Selman WR. Pharmacological management of acromegaly: a current perspective. Neurosurg Focus. 2010;29:E14.

3. Sesmilo G. Epidemiology of acromegaly in Spain. Endocrinol Nutr. 2013;60:470-4. 
4. Mestron A, Webb SM, Astorga R, Benito P, Catala M, Gaztambide S, et al. Epidemiology, clinical characteristics, outcome, morbidity and mortality in acromegaly based on the Spanish Acromegaly Registry (Registro Espanol de Acromegalia, REA). Eur J Endocrinol. 2004;151:439-46.

5. Luque-Ramirez M, Carreno A, Alvarez Escola C, del Pozo Pico C, Varela da Costa C, Fajardo Montanana $\mathrm{C}$, et al. The OASIS study: therapeutic management of acromegaly in standard clinical practice. Assessment of the efficacy of various treatment strategies. Endocrinol Nutr. 2011;58:478-86.

6. Colao A, Auriemma RS, Lombardi G, Pivonello R. Resistance to somatostatin analogs in acromegaly. Endocr Rev. 2011;32:247-71.

7. Melmed S, Colao A, Barkan A, Molitch M, Grossman AB, Kleinberg D, et al. Guidelines for acromegaly management: an update. J Clin Endocrinol Metab. 2009;94:1509-17.

8. Cordido F, Garcia Arnes JA, Marazuela Aspiroz M, Torres Vela E. Practical guidelines for diagnosis and treatment of acromegaly. Endocrinol Nutr. 2013;60, 457 e451-457 e415.

9. Marzullo P, Ferone D, Di Somma C, Pivonello R, Filippella M, Lombardi G, et al. Efficacy of combined treatment with lanreotide and cabergoline in selected therapy-resistant acromegalic patients. Pituitary. 1999;1:115-20.

10. Selvarajah D, Webster J, Ross R, Newell-Price J. Effectiveness of adding dopamine agonist therapy to long-acting somatostatin analogues in the management of acromegaly. Eur J Endocrinol. 2005;152:56974.

11. Gatta B, Hau DH, Catargi B, Roger P, Tabarin A. Re-evaluation of the efficacy of the association of cabergoline to somatostatin analogues in acromegalic patients. Clin Endocrinol (Oxf). 2005;63:477-8.

12. Jallad RS, Bronstein MD. Optimizing medical therapy of acromegaly: beneficial effects of cabergoline in patients uncontrolled with long-acting release octreotide. Neuroendocrinology. 2009;90:82-92.

13. Mattar P, Alves Martins MR, Abucham J. Short- and long-term efficacy of combined cabergoline and octreotide treatment in controlling IGF-I levels in acromegaly. Neuroendocrinology. 2010;92:120-7.

14. Vilar L, Azevedo MF, Naves LA, Casulari LA, Albuquerque JL, Montenegro RM, et al. Role of the addition of cabergoline to the management of acromegalic patients resistant to long term treatment with octreotide LAR. Pituitary. 2011;14:148-56.

15. Sandret L, Maison P, Chanson P. Place of cabergoline in acromegaly: a meta-analysis. J Clin Endocrinol Metab. 2011;96:1327-35.

16. Parkinson C, Trainer PJ. Pegvisomant: a growth hormone receptor antagonist for the treatment of acromegaly. Growth Horm IGF Res. 2000;10 Suppl B:S119-23.

17. Trainer PJ, Drake WM, Katznelson L, Freda PU, Herman-Bonert V, van der Lely AJ, et al. Treatment of acromegaly with the growth hormone-receptor antagonist pegvisomant. N Engl J Med. 2000;342:1171-7.

18. van der Lely AJ, Hutson RK, Trainer PJ, Besser GM, Barkan AL, Katznelson L, et al. Long-term treatment of acromegaly with pegvisomant, a growth hormone receptor antagonist. Lancet. 2001;358:1754-9.

19. Schreiber I, Buchfelder M, Droste M, Forssmann K, Mann K, Saller B, et al. Treatment of acromegaly with the GH receptor antagonist pegvisomant in clinical practice: safety and efficacy evaluation from the German Pegvisomant Observational Study. Eur J Endocrinol. 2007;156:75-82.

20. Feenstra J, de Herder WW, ten Have SM, van den Beld AW, Feelders RA, Janssen JA, et al. Combined therapy with somato- statin analogues and weekly pegvisomant in active acromegaly. Lancet. 2005;365:1644-6.

21. Neggers SJ, de Herder WW, Janssen JA, Feelders RA, van der Lely AJ. Combined treatment for acromegaly with long-acting somatostatin analogs and pegvisomant: long-term safety for up to 4.5 years (median 2.2 years) of follow-up in 86 patients. Eur J Endocrinol. 2009;160:529-33.

22. Jorgensen JO, Feldt-Rasmussen U, Frystyk J, Chen JW, Kristensen LO, Hagen C, et al. Cotreatment of acromegaly with a somatostatin analog and a growth hormone receptor antagonist. J Clin Endocrinol Metab. 2005;90:5627-31.

23. van der Lely AJ, Bernabeu I, Cap J, Caron P, Colao A, Marek J, et al. Coadministration of lanreotide Autogel and pegvisomant normalizes IGF1 levels and is well tolerated in patients with acromegaly partially controlled by somatostatin analogs alone. Eur J Endocrinol. 2011;164:325-33.

24. Neggers SJ, Franck SE, de Rooij FW, Dallenga AH, Poublon RM, Feelders RA, et al. Long-term efficacy and safety of pegvisomant in combination with long-acting somatostatin analogs in acromegaly. J Clin Endocrinol Metab. 2014;99: 3644-52.

25. Nellesen D, Truong H, Oh D, Neary MP, Ludlam WH. Systematic review of real-world evidence on treatment of acromegaly. Endocrine Rev. 2014;35:SUN-0606.

26. Ramirez C, Espinosa de los Monteros AL, Sosa E, Franco JM, Vargas G, Gonzalez B, et al. Long-term efficacy of cabergo-line addition to ongoing octreotide LAR therapy in patients with acromegaly. Endocrine Rev. 2014;35:SUN-0611. 
27. Neggers SJ, van Aken MO, Janssen JA, Feelders RA, de Herder WW, van der Lely AJ. Long-term efficacy and safety of combined treatment of somatostatin analogs and pegvisomant in acromegaly. $\mathrm{J}$ Clin Endocrinol Metab. 2007;92: 4598-601.

28. Bianchi A, Valentini F, Iuorio R, Poggi M, Baldelli R, Passeri M, et al. Long-term treatment of somatostatin analog-refractory growth hormone-secreting pituitary tumors with pegvisomant alone or combined with long-acting somatostatin analogs: a retrospective analysis of clinical practice and outcomes. J Exp Clin Cancer Res. 2013;32:40.

29. Trainer PJ. ACROSTUDY: the first 5 years. Eur J Endocrinol. 2009;161 Suppl 1:S19-24.

30. van der Lely AJ, Biller BM, Brue T, Buchfelder M, Ghigo E, Gomez R, et al. Long-term safety of pegvisomant in patients with acromegaly: comprehensive review of 1288 subjects in ACROSTUDY. J Clin Endocrinol Metab. 2012;97: 1589-97.

31. Giustina A, Bonadonna S, Bugari G, Colao A, Cozzi R, Cannavo S, et al. High-dose intramuscular octreotide in patients with acromegaly inadequately controlled on conventional somato- statin analogue therapy: a randomised controlled trial. Eur J Endocrinol. 2009;161:331-8.

32. Stalla GK, Ferone D, Colao A. Is clinical practice reflective of acromegaly treatment guidelines? Results from a survey of treating physicians in 45 countries. Endocr Rev. 2014;35:SUN- 0619.

33. Schade R, Andersohn F, Suissa S, Haverkamp W, Garbe E. Dopamine agonists and the risk of cardiacvalve regurgitation. N Engl J Med. 2007;356:29-38.

34. Maione L, Garcia C, Bouchachi A, Kallel N, Maison P, Salenave S, et al. No evidence of a detrimental effect of cabergoline therapy on cardiac valves in patients with acromegaly. J Clin Endocrinol Metab. 2012;97:E1714-9.

35. Halperin I, Aller J, Varela C, Mora M, Abad A, Doltra A, et al. No clinically significant valvular regurgitation in long-term cabergoline treatment for prolactinoma. Clin Endocrinol (Oxf). 2012;77:27580.

36. Drake WM, Stiles CE, Howlett TA, Toogood AA, Bevan JS, Steeds RP, et al. A cross-sectional study of the prevalence of cardiac valvular abnormalities in hyperprolactinemic patients treated with ergotderived dopamine agonists. J Clin Endocrinol Metab. 2014;99:90-6.

37. Biering H, Saller B, Bauditz J, Pirlich M, Rudolph B, Johne A, et al. Elevated transaminases during medical treatment of acromegaly: a review of the German pegvisomant surveillance experience and a report of a patient with histologically proven chronic mild active hepatitis. Eur J Endocrinol. 2006;154:213-20.

38. Baldelli R, Battista C, Leonetti F, Ghiggi MR, Ribaudo MC, Paoloni A, et al. Glucose homeostasis in acromegaly: effects of long- acting somatostatin analogues treatment. Clin Endocrinol (Oxf). 2003;59:492-9.

39. De Marinis L, Bianchi A, Fusco A, Cimino V, Mormando M, Tilaro L, et al. Long-term effects of the combination of pegvisomant with somatostatin analogs (SSA) on glucose homeostasis in non- diabetic patients with active acromegaly partially resistant to SSA. Pituitary. 2007;10:227-32.

40. Puig-Domingo M. Treatment of acromegaly in the era of personalized and predictive medicine. Clin Endocrinol (Oxf). 2015;83:3-14 